\title{
The effect of $A B C B 1$ polymorphism on sirolimus in renal transplant recipients: a meta-analysis
}

\author{
Shuai Shao, ${ }^{1,2}$ Lei Hu ${ }^{1}$, Zaigang Han ${ }^{2}$, Kelu Hou ${ }^{1}$, Huihui Fang ${ }^{1}$, Guijie Zhang ${ }^{1}$, Yufei Feng ${ }^{1}$, Lin Huang ${ }^{1}$ \\ ${ }^{1}$ Department of Pharmacy, Peking University People's Hospital, Beijing 100044, China; ${ }^{2}$ Department of Pharmacy, Affiliated Hospital of Beihua \\ University, Jilin 132011, China \\ Contributions: (I) Conception and design: L Huang; (II) Administrative support: L Huang, Y Feng; (III) Provision of study materials: L Hu, K Hou; \\ (IV) Collection and assembly of data: S Shao, ZG Han, H Fang, G Zhang; (V) Data analysis and interpretation: S Shao; (VI) Manuscript writing: All \\ authors; (VII) Final approval of manuscript: All authors. \\ Correspondence to: Yufei Feng, MS; Lin Huang, PhD. Department of Pharmacy, Peking University People's Hospital, No. 11 Xizhimen South Street, \\ Xicheng District, Beijing 100044, China. Email: fenyufei@126.com; huanglin@pkuph.edu.cn.
}

Background: Sirolimus (SRL) is an immunosuppressive drug and substrate of the P-glycoprotein (P-GP) encoded by $A B C B 1$. The relationship between $A B C B 1$ polymorphism and the pharmacokinetics of SRL in different studies were conflicting in renal transplant recipients. Thus, this meta-analysis aims to investigate the influence of $A B C B 1 \mathrm{C} 3435 \mathrm{~T}, \mathrm{C} 1236 \mathrm{~T}$, and G2677T/A polymorphisms on the dose-adjusted trough level (C/D) of SRL in renal transplant recipients.

Methods: PubMed, Embase, and the Cochrane Library were searched for relevant studies. The quality of each eligible study was assessed according to Newcastle-Ottawa Scale. The STATA 15.0 was adopted to perform the meta-analysis. The fixed-effects model was used for pooled results with low heterogeneity $\left(\mathrm{I}^{2} \leq 50 \%\right)$; otherwise, the random-effects model was used.

Results: A total of 6 studies were included in the meta-analysis. Results of pooled analysis showed no significant association of SRL C/D ratio with ABCB1 C3435T polymorphism. The subgroup analysis based on different ethnic groups and different time-points after SRL initiation in renal transplant recipients were also conducted. No significant association was observed in these subgroups. Significant associations were showed between $A B C B 1 \mathrm{C} 1236 \mathrm{~T}$ polymorphism and the $\mathrm{C} / \mathrm{D}$ ratio of SRL in the homozygous model (TT vs. CC; WMD: -45.54; 95\% CI: -75.15, -15.94; P=0.003), and also in subgroup of Caucasian (TT vs. CC; WMD: -46.57 ; 95\% CI: $-91.90,-1.25$; $\mathrm{P}=0.044$ and TT vs. CC + CT; WMD: $-52.10 ; 95 \%$ CI: -95.38, -8.82; $\mathrm{P}=0.018)$. Significant differences were found in association between the $A B C B 1 \mathrm{G} 2677 \mathrm{~T} / \mathrm{A}$ polymorphism and the C/D ratio of SRL, including the homozygous model (TT vs. GG; WMD: -76.47; 95\% CI: $-126.37,-26.58 ; \mathrm{P}=0.003)$, the heterozygous model (GT vs. GG, WMD: 178.62; 95\% CI: 125.03, 232.22; $\mathrm{P}=0.000)$, the dominant model (GT + TT vs. GG; WMD: 82.23; 95\% CI: 36.28, 128.17; P=0.000), the recessive model (TT vs. GG + GT; WMD: -179.38 ; 95\% CI: $-283.33,-75.42 ; \mathrm{P}=0.001$ ), and the overdominant model (GT vs. GG + TT; WMD: 199.44; 95\% CI: 84.84, 314.05; P=0.001).

Conclusions: No significant association exists between $A B C B 1 \mathrm{C} 3435 \mathrm{~T}$ polymorphism and the C/D ratio of SRL in renal transplant recipients. To achieve target therapeutic concentrations, ABCB1 C1236T homozygous mutant TT genotype will require a higher dose of sirolimus than wild type GG, especially in Caucasian renal transplant recipients. ABCB1 G2677T/A TT genotype will also need a higher dose of sirolimus genotype. Genotyping of $A B C B 1$ might help to improve the individualization of SRL for renal transplant recipients. Further studies are expected to provide high-quality evidence.

Keywords: Sirolimus; $A B C B 1$; pharmacokinetics; meta-analysis

Submitted Feb 06, 2020. Accepted for publication Mar 16, 2020.

doi: $10.21037 /$ tau.2020.03.42

View this article at: http://dx.doi.org/10.21037/tau.2020.03.42 


\section{Introduction}

Renal transplantation is one of the most effective treatments for end-stage renal disease (1). The emergence of immunosuppression drugs has dramatically improved the long-term survival of allografts and patients (2). Sirolimus (SRL), also known as rapamycin, which is a potent immunosuppressive drug used for prophylaxis of allograft rejection after renal transplantation (3). SRL shows substantial interindividual differences in pharmacokinetics (4). To achieve the desired efficacy and avoid the adverse reaction, monitoring the blood concentration of SRL is necessary (5). SRL is the substrate of P-glycoprotein (P-GP), an efflux transporter encoded by the $A B C B 1$ gene (6). P-GP transports SRL from the intracellular to the extracellular domain and influencing SRL pharmacokinetics (7). The expression and production of $A B C B 1$ are related to single nucleotide polymorphisms (SNPs) (8). The genetic polymorphisms of $A B C B 1$ have been considered as significant determinants of SRL pharmacokinetic (9).

Increasing studies have been conducted to investigate the influence of genetic polymorphisms of $A B C B 1$ on SRL trough blood concentrations and pharmacokinetic parameters in renal transplantation $(4,10,11)$. While until now, the results of the $A B C B 1$ genotype on SRL pharmacokinetics are contradictory (12). Miao et al. (10) evaluated the relationship between the $A B C B 13435 \mathrm{C}>\mathrm{T}$ genotype and C/D (trough concentrations/dose ratios) of SRL, but no significant association was observed. However, Sam et al. (13) reported that $A B C B 13435 \mathrm{C}>\mathrm{T}$ genotype was significantly associated with $\log \mathrm{C} / \mathrm{D}$ of SRL. More than 50 genotypes have been studied in $A B C B 1$, but most widely studied are the $3435 \mathrm{C}>\mathrm{T}$ in exon $26,1236 \mathrm{C}>\mathrm{T}$ in exon 12 , and three alleles $2677 \mathrm{G}>\mathrm{T} / \mathrm{A}$ in exon 21 (14). Although there are various studies on the correlation between $A B C B 1$ polymorphisms and dose-adjusted concentration of SRL, there is no systematical evidence about the effect of $A B C B 1$ polymorphisms on the dosage adjusted concentration of SRL. Therefore, to explore the relationship between $A B C B 1$ C3435T, C1236T, G2677T/A genotypes, and the SRL dose requirement in kidney transplant recipients, we performed the meta-analysis in related studies.

\section{Methods}

The report followed the guidelines set out in the Preferred
Reporting Items for Systematic Review and Meta-Analyses (PRISMA) Statement (15).

\section{Search strategy}

The studies were searched in the databases of PubMed, Embase, and the Cochrane Library up to November 2019. To investigate the association between ABCB1 polymorphism and pharmacokinetics of sirolimus in renal transplant recipients, we combined search terms as (kidney transplantation or renal transplantation) and (sirolimus or rapamycin or rapamune or AY-22989 or I-2190A) and (multidrug resistance-1 or ABCB1 or MDR1 or p-glycoprotein or P-GP or C3435T or C1236T or G2677T or G2677A or G2677T/A or rs 1045642 or rs 1128503 or rs2032582) and (polymorphism* or variant or mutation or genotype).

\section{Study selection}

Two reviewers evaluated studies for the titles, abstracts, and the full texts of the candidate articles $(n=138)$ independently and in duplicate. Studies were enrolled according to the following inclusion criteria: (I) studies that assessed the association between $A B C B 1 \mathrm{C} 3435 \mathrm{~T}, \mathrm{C} 1236 \mathrm{~T}$ or G2677T/A polymorphisms and sirolimus metabolism; (II) provided original data including sirolimus dosage adjusted concentration $[\mathrm{C} / \mathrm{D}$ ratio $=$ concentration $(\mathrm{ng} / \mathrm{mL}) /$ dose $(\mathrm{mg} / \mathrm{kg})]$ after renal transplantation; (III) studies included detailed genotyping data of $A B C B 1$. Exclusion criteria were (I) incomplete genotype data; (II) insufficient $\mathrm{C} / \mathrm{D}$ data; (III) articles only with an abstract.

\section{Data extraction}

Two independent researchers extracted the following information from each study: lead author, publication year, country of origin, ethnicity, mean or range of age, sample size, sex, therapy time (the time of renal transplant recipients treated with SRL), weight-adjusted dosage of sirolimus [the daily dose of SRL (mg) divided by the weight $(\mathrm{mg} / \mathrm{kg} /$ day)], target therapeutic window (rang of dosage adjusted trough steady-state blood levels of SRL), method of genotype measured, method of concentration measured. Furthermore, the C/D ratios were shown by the form of mean \pm standard deviation (SD). If the studies only provided minimum and maximum; instead, the mean \pm standard 


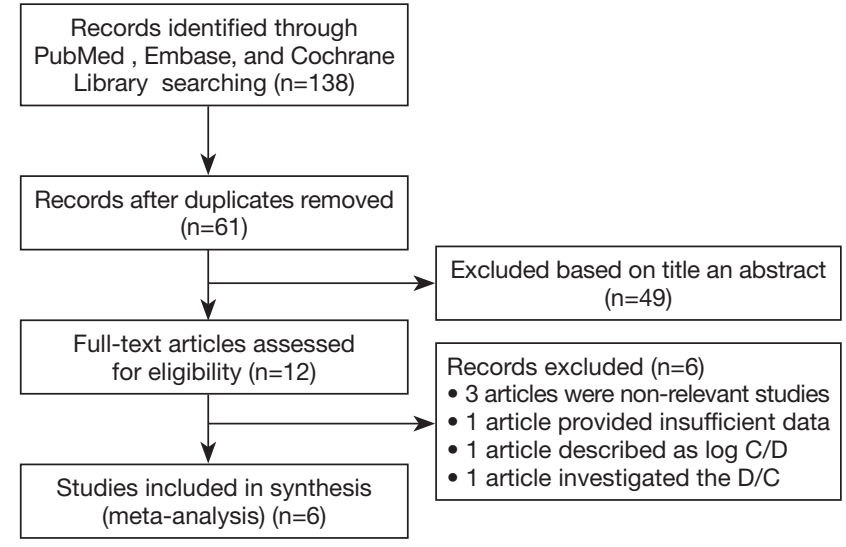

Figure 1 Flow chart of the study selection process.

deviation was estimated by the method, which was reported by Jiang et al. (16).

\section{Quality assessment}

The quality assessment of included eligible studies was conducted by the Newcastle-Ottawa Scale (NOS) (17). It consisted of three parts: a selection of participants (four items), comparability of cases, and control groups (two items), adequacy of Outcome (three items). Thus, the quality assessment score ranged from zero to nine-point. The score seven points or more were expressed high quality and insignificant risk of bias, and if less than seven points represent low or moderate quality, considered as high or moderate risk of bias.

\section{Statistical analysis}

Statistical analyses were conducted with Stata (release 15.0; Stata Corporation, College Station, TX, USA) software. The weighted mean difference (WMD) and 95\% confidence intervals (CIs) on forest plots of sirolimus C/ D ratio among different C1236T, C3435T and G2677T/A genotypes were evaluated. We examined the value of WMD for the allelic model, homozygous model, heterozygous model, dominant model, recessive model, over-dominant model. I-squared $\left(\mathrm{I}^{2}\right)$ statistics estimated the heterogeneity. The fixed effects model was initially applied. When heterogeneity existed as $\mathrm{I}^{2}>50 \%$, and the random effects model was used. To evaluate the influence of ethnicity and therapy time differences in heterogeneity, subgroup analysis based on ethnicity and therapy time was performed.
Moreover, deviation from the Hardy-Weinberg equilibrium (HWE) of each eligible study was assessed, and if $\mathrm{P}<0.05$ was considered as disequilibrium. Studies not in HWE were subjected to sensitivity analysis. We performed a sensitivity analysis for the influence of each study on the stability of the results. Publication bias was examined by the symmetry of the funnel plot and evaluated by Egger's test $(\mathrm{P}<0.05$ was considered as significant publication bias).

\section{Results}

\section{Studies selection and characteristics}

The flow diagram for the study selection process is shown in Figure 1. After a preliminary online search, a total of 138 potentially relevant articles, with 58 from PubMed, 36 from Embase, and 44 from the Cochrane Library, were named for further evaluations. There were 61 studies removed after duplicates. Then 49 studies were screened for inclusion by the titles and abstracts articles not associated with the $\mathrm{ABCB} 1$ polymorphisms and the C/D ratio of SRL. Six studies were excluded: 3 articles were non-relevant studies; 1 article supplied insufficient data; 1 article described as log $\mathrm{C} / \mathrm{D} ; 1$ article investigated the $\mathrm{D} / \mathrm{C}$ ratio. Thus, there were 6 eligible studies $(10,11,18-21)$ described the association of $A B C B 1$ polymorphism with the C/D ratio of SRL. These studies were conducted in different countries including China (10,18,19), Spain (20), Belgium (21), France (11). The detailed characteristics, $A B C B 1$ genotype distributions, and dose-adjusted concentration of sirolimus of these included studies were shown in Tables 1 and 2.

\section{Study quality assessment}

The quality of the included eligible studies was evaluated according NOS. The scores of these studies were between 6 and 9 , which represented high quality and minimal risk of bias. The results of the quality assessment were showed in Table 2. The distribution of the genotypes of all included studies was in HWE except for C1236T (P-HWE $=0.042$ ) of Lee et al. (18).

\section{Association between ABCB1 C3435T polymorphism and C/D ratio of sirolimus}

A total of six studies analyzed the association between $A B C B 1 \mathrm{C} 3435 \mathrm{~T}$ polymorphism and the $\mathrm{C} / \mathrm{D}$ ratio of SRL. As shown in Table 3, three studies were conducted 
Table 1 The characteristics of included eligible studies

\begin{tabular}{|c|c|c|c|c|c|c|c|c|c|c|c|c|}
\hline Study & Year & Country & Ethnicity & $\mathrm{N}$ & $\mathrm{M} / \mathrm{F}$ & Age [years] & $\begin{array}{l}\text { Therapy time } \\
\text { (month) }\end{array}$ & $\begin{array}{l}\text { Weight-adjusted dosage of } \\
\text { sirolimus }(\mathrm{mg} / \mathrm{kg} / \mathrm{day})\end{array}$ & Target therapeutic window $(\mathrm{ng} / \mathrm{mL})$ & Genotype & $\begin{array}{l}\text { Method of genotype } \\
\text { measured }\end{array}$ & $\begin{array}{l}\text { Method of concentration } \\
\text { measured }\end{array}$ \\
\hline Rodriguez-Jiménez (20) & 2017 & Spain & Caucasian & 36 & $28 / 8$ & $58 \pm 9$ & $\geq 1$ & $\begin{array}{l}\text { CC: } 0.077 \pm 0.053 ; \text { CT: } \\
0.042 \pm 0.012 ; \text { T: } 0.052\end{array}$ & \multicolumn{2}{|c|}{$\begin{array}{l}\text { CC: } 11.219 \pm 7.884 ; \text { CT: } 10.957 \pm 4.586 ; \text { С } 3435 T \\
\text { Пт: } 11.660 \pm 5.352\end{array}$} & PCR-RFLP & $\begin{array}{l}\text { Microparticle enzyme } \\
\text { immunoassay technique }\end{array}$ \\
\hline Li (19) & 2015 & China & Asian & 43 & $30 / 13$ & 35 [34-46] & $>1$ & $0.04-0.06$ & $5-10$ & $\begin{array}{l}\text { C1236T G2677T } \\
\text { C3435T }\end{array}$ & PCR & $\begin{array}{l}\text { Automated enzyme } \\
\text { immunoassay analyzer }\end{array}$ \\
\hline Lee (18) & 2014 & China & Asian; Han nationality & 85 & $65 / 20$ & $42.9 \pm 10.4$ & $\geq 3$ & - & $5-10$ & $\begin{array}{l}\text { C1236T G2677T/A } \\
\text { C3435T }\end{array}$ & PCR & HPLC \\
\hline Miao (10) & 2008 & China & Asian; Han nationality & 50 & $39 / 11$ & $42 \pm 15$ & $\geq 6$ & $\begin{array}{l}\text { CC: } 0.025 \pm 0.006 ; \text { CT: } \\
0.024 \pm 0.004 ; \text { T: } 0.025 \pm 0.003\end{array}$ & 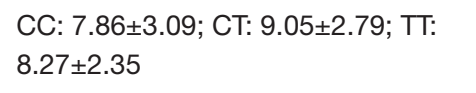 & С3435T & PCR-RFLP & HPLC \\
\hline Mourad (21) & 2005 & Belgium & $\begin{array}{l}\text { Caucasian; Africans; } \\
\text { South Asian }\end{array}$ & - & - & - & $6.2-285.3$ & $0.11 \pm 0.06$ & $5-15$ & $\begin{array}{l}\text { C1236T G2677T } \\
\text { C3435T }\end{array}$ & PCR & LC-MS/MS \\
\hline Anglicheau (11) & 2005 & France & $\begin{array}{l}\text { Caucasian; Black; } \\
\text { Caribbean }\end{array}$ & 51 & $30 / 21$ & 43.7 [19.9-61.0] & 3 & $0.025-0.476$ & $10-20$ & $\begin{array}{l}\text { C1236T G2677T/A } \\
\text { C3435T }\end{array}$ & PCR & HPLC \\
\hline
\end{tabular}

$\mathrm{M} / \mathrm{F}$, male/female.

Table 2 The genotype distributions and dose-adjusted concentration of sirolimus of included eligible studies

\begin{tabular}{|c|c|c|c|c|c|c|c|c|c|c|c|c|c|c|c|c|c|c|c|c|c|c|}
\hline \multirow{2}{*}{ Study } & \multirow{2}{*}{$\begin{array}{l}\text { Postoperative } \\
\text { time (month) }\end{array}$} & \multicolumn{5}{|c|}{ С $3435 \mathrm{~T}$} & \multicolumn{5}{|c|}{ C1236T } & \multicolumn{5}{|c|}{ G2677T } & \multicolumn{5}{|c|}{ G2677 mutant } & \multirow{2}{*}{$\begin{array}{l}\text { NOS } \\
\text { Score }\end{array}$} \\
\hline & & Cases (n) & CC & CT & $\pi$ & HWE & Cases (n) & CC & CT & $\pi$ & HWE & Cases $(n)$ & GG & GT & $\pi$ & HWE & Cases (n) & GG & $\mathrm{G} /$ mutant & mutant/mutant & HWE & \\
\hline $\begin{array}{l}\text { Rodríguez- } \\
\text { Jiménez }\end{array}$ & 3 & $3 / 13 / 1$ & $183.70 \pm 166.67$ & $301.18 \pm 238.95$ & 159.31 & 0.060 & - & - & - & - & - & - & - & - & - & - & - & - & - & - & - & 6 \\
\hline $\mathrm{Li}$ & $>1$ & 18/20/5 & $442.45 \pm 65.93$ & $338.1 \pm 80.25$ & $383.85 \pm 82.98$ & 0.096 & 8/20/15 & $246.6 \pm 59$ & $446.85 \pm 91.03$ & $163.75 \pm-57.43$ & 0.770 & $7 / 16 / 11$ & $246.6 \pm 59$ & $446.85 \pm 91.03$ & $163.75 \pm 57.43$ & 0.790 & - & - & - & - & - & 7 \\
\hline Lee & $\geq 3$ & 29/43/13 & $262.79 \pm 118.37$ & $260.63 \pm 103.67$ & $272.16 \pm 88.77$ & 0.652 & 6/47/32 & $257.03 \pm 62.79$ & $269.24 \pm 84.49$ & $271.23 \pm 106.95$ & 0.042 & - & - & - & - & - & $18 / 34 / 33$ & $261.45 \pm 58.12$ & $258.49 \pm 81.57$ & $267.37 \pm 112.60$ & 0.108 & 8 \\
\hline Miao & $\geq 6$ & $12 / 27 / 8$ & $334.59 \pm 133.69$ & $377.88 \pm 127.97$ & $344.92 \pm 121.26$ & 0.281 & - & - & - & - & - & - & - & - & - & - & - & - & - & - & - & 8 \\
\hline Mourad & $6.2-285.3$ & $26 / 44 / 15$ & $447.21 \pm 194.58$ & $375.13 \pm 156.55$ & $569.79 \pm 261.77$ & 0.626 & $30 / 41 / 14$ & $447.21 \pm 194.58$ & $582.90 \pm 255.22$ & $408.83 \pm 181.30$ & 0.998 & $32 / 39 / 14$ & $57.56 \pm 189.40$ & $575.70 \pm 258.82$ & $408.83 \pm 181.30$ & 0.717 & - & - & - & - & - & 7 \\
\hline Anglicheau & 3 & $21 / 21 / 9$ & $186 \pm 128$ & $139 \pm 77$ & $176 \pm 75$ & 0.360 & $116 / 23 / 12$ & $198 \pm 146$ & $150 \pm 70$ & $150 \pm 73$ & 0.967 & - & - & - & - & - & $22 / 20 / 9$ & $184 \pm 125$ & $144 \pm 80$ & $166 \pm 77$ & 0.250 & 9 \\
\hline
\end{tabular}


Table 3 Results of association between $A B C B 1$ C3435T polymorphism and C/D ratio of sirolimus

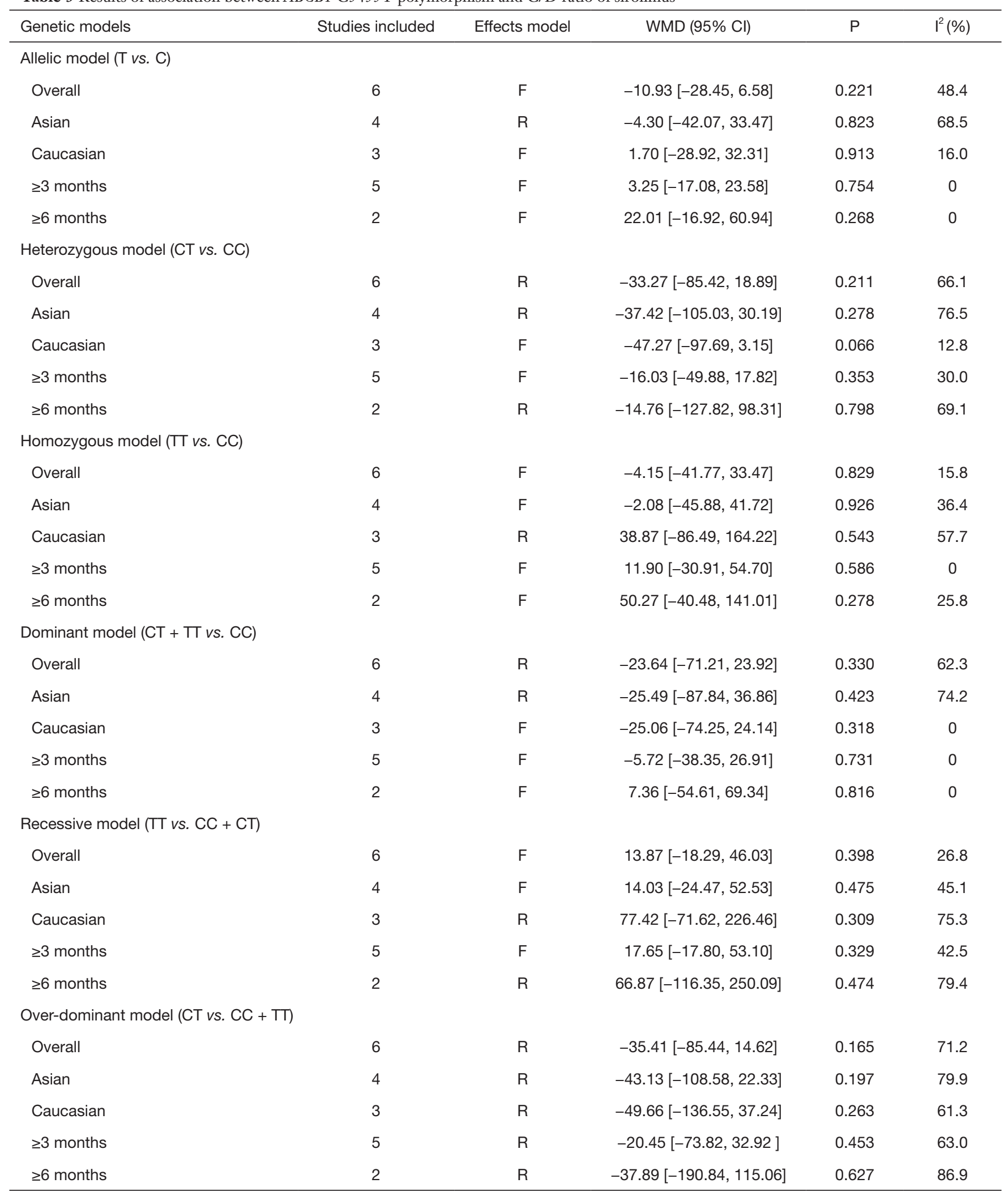

WMD, weighted mean difference; F, fixed model; $\mathrm{R}$, random model; $95 \% \mathrm{Cl}$, 95\% confidence interval. 
in China $(10,18,19)$, and the others were respectively in Spain (20), Belgium (21), and France (11). According to the statistical analysis in total populations via different genetic models, no significant association was observed between $A B C B 1 \mathrm{C} 3435 \mathrm{~T}$ polymorphism and C/D ratio of SRL. The subgroup analyses were performed according to the ethnicity of recipients (grouped as Asian or Caucasian) and the interval after transplantation (grouped as over 3 months or over 6 months). No significant association was found in subgroups of ethnicity and the interval after transplantation. Overall, there was no significant effect of $A B C B 1 \mathrm{C} 3435 \mathrm{~T}$ polymorphism on the dose-adjusted trough level of SRL.

\section{Association between ABCB1 C1236T polymorphism and C/D ratio of sirolimus}

Four included studies evaluated the association between $A B C B 1 \mathrm{C} 1236 \mathrm{~T}$ polymorphism and C/D ratio of SRL. As shown in Table 4, two studies were conducted in China $(18,19), 1$ in Belgium (21), and 1 in France (11). According to the statistical analysis, significant association were observed in the homozygous model of all patients (TT $v s$. CC; WMD: -45.54; 95\% CI: -75.15, -15.94; P=0.003), subgroup of Caucasian in the homozygous model (TT vs. CC; WMD: -46.57; 95\% CI: -91.90, -1.25; P=0.044), subgroup of Asian in the dominant model (CT + TT vs. CC; WMD: 55.11; 95\% CI: 21.34, 88.87; $\mathrm{P}=0.001)$, and subgroup of Caucasian in the recessive model (TT vs. CC + CT; WMD: -52.10 ; 95\% CI: -95.38, -8.82; $\mathrm{P}=0.018)$. The forest plots were shown in Figures S1-S4. The subjects with TT genotype in Caucasian subgroup $A B C B 1 \mathrm{C} 1236 \mathrm{~T}$ had a lower C/D ratio and needed higher sirolimus dose than those with CC genotype.

\section{Association between ABCB1 G2677T/A polymorphism and C/D ratio of sirolimus}

The $A B C B 12677 \mathrm{G}>\mathrm{T} / \mathrm{A}$ mutation could lead to two changes of an amino acid (from alanine to serine or threonine) (22). The genotypes for the $A B C B 12677 \mathrm{G}>$ T/A SNP were classified as follows: wild type (G/G), heterozygous (G/T or G/A) and homozygous for the variant (T/T, T/A or A/A). Due to the diversity of this genotype, data can not be merged simply.

Two studies $(19,21)$ assessed the influence of $A B C B 1$ G2677T polymorphism on the dose-adjusted trough level of SRL, and the summarized results were shown in
Table 5. According to the statistical analysis, significant differences were found in association between the $A B C B 1$ G2677T polymorphism and the C/D ratio of SRL in the heterozygous model (GT vs. GG, WMD: 178.62; 95\% CI: 125.03, 232.22; $\mathrm{P}=0.000$ ), the homozygous model (TT vs. GG; WMD: -76.47; 95\% CI: -126.37, -26.58; P=0.003), the dominant model (GT + TT vs. GG; WMD: 82.23; 95\% CI: 36.28, 128.17; $\mathrm{P}=0.000$ ), the recessive model (TT vs. GG + GT; WMD: -179.38 ; 95\% CI: -283.33, -75.42; $\mathrm{P}=0.001$ ), and the over-dominant model (GT vs. GG + TT; WMD: 199.44; 95\% CI: 84.84, 314.05; P=0.001). The forest plots were shown in Figures $S 5-S 9$.

Two studies $(11,18)$ assessed the influence of $A B C B 1$ G2677mutant polymorphism on the C/D ratio of SRL. Mutant type included TT, TA or AA in both of these studies. The summarized results were shown in Table 6. The results of heterogeneity within all genetic models were 0 . Moreover, no significant difference was found in association with the $A B C B 1$ G2677mutant polymorphism with the C/ $\mathrm{D}$ ratio of SRL.

\section{Sensitivity analysis}

As shown in Table 2, only one study (18) included in the meta-analysis was a departure from $\operatorname{HWE}(\mathrm{P}<0.05)$. A sensitivity analysis was performed by sequential omission of each eligible study to assess the influence of the individual data on the pooled WMDs. The results revealed that the departure from HWE of study has no major impact. Sensitivity analysis to evaluate the ethnicity and therapy time showed that no individual study influenced the pooled estimate significantly. The results are shown in Figures S10-S13. None of the studies had an individually considerable influence on the impact of $A B C B 1 \mathrm{C} 3435 \mathrm{~T}$, C1236T, G2677T/A. Sensitivity analyses suggested that this meta-analysis was steady.

\section{Estimation of publication bias}

The potential publication bias of eligible studies was assessed by the funnel plot, Egger's test, and Begg's test. As shown in Figures S14-S17, the funnel plots did not provide evidence of obvious asymmetry. The Egger's test and Begg's test for publication bias were not statistically significant in all the genetic models of $A B C B 1 \mathrm{C} 3435 \mathrm{~T}, \mathrm{C} 1236 \mathrm{~T}$ (Table S1), because of the number of G2677T/A studies was small, the Egger's test cannot be displayed. 
Table 4 Results of the association between ABCB1 C1236T polymorphism and dose-adjusted concentration of sirolimus

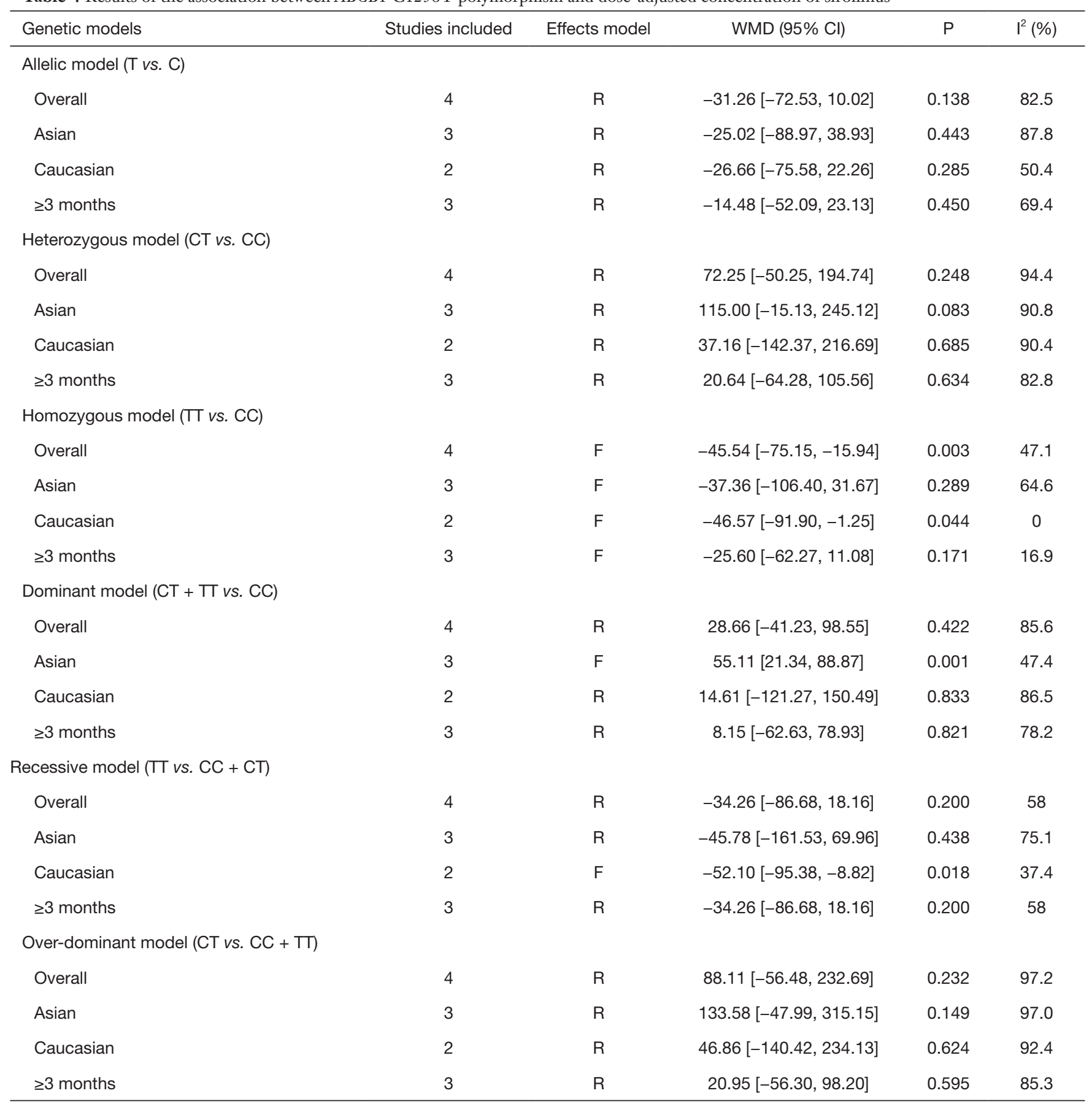

WMD, weighted mean difference. F, fixed model; R, random model; 95\% Cl, 95\% confidence interval. 
Table 5 Results of association between $A B C B 1$ G2677T polymorphism and C/D ratio of sirolimus

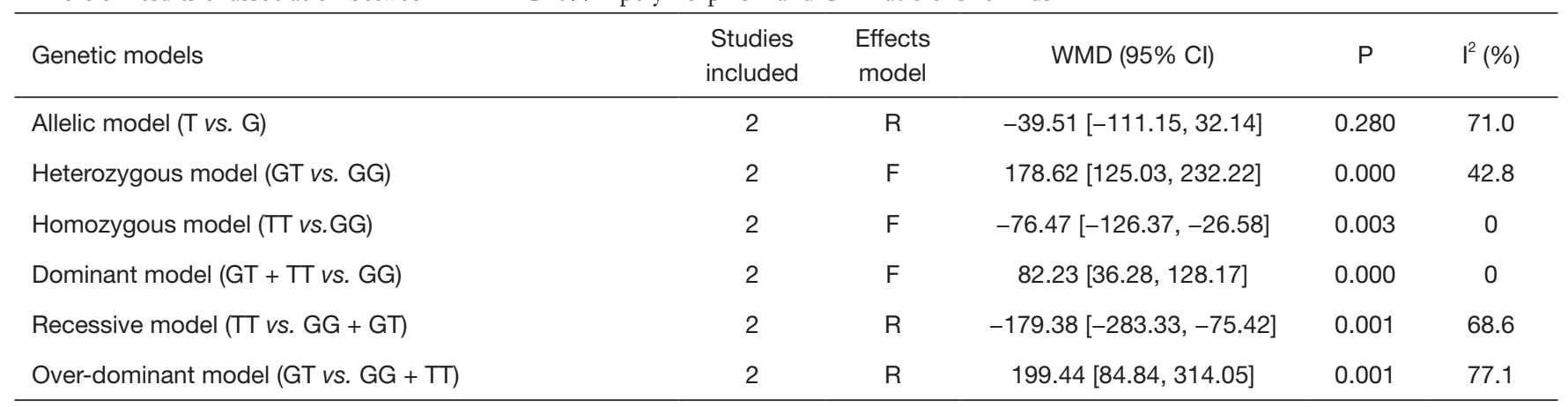

WMD, weighted mean difference. F, fixed model; R, random model; 95\% Cl, 95\% confidence interval.

Table 6 Results of association between $A B C B 1$ G2677mutant polymorphism and C/D ratio of sirolimus

\begin{tabular}{|c|c|c|c|c|c|}
\hline Genetic models & $\begin{array}{l}\text { Studies } \\
\text { included }\end{array}$ & $\begin{array}{l}\text { Effects } \\
\text { model }\end{array}$ & WMD $(95 \% \mathrm{Cl})$ & $\mathrm{P}$ & $\mathrm{I}^{2}(\%)$ \\
\hline Allelic model (mutant vs. G) & 2 & $\mathrm{~F}$ & $-2.70[-24.09,18.69]$ & 0.805 & 0 \\
\hline Heterozygous model (G/mutant vs. GG) & 2 & $\mathrm{~F}$ & $-13.0[-45.77,19.76]$ & 0.437 & 0 \\
\hline Homozygous model (mutant/mutant vs. GG) & 2 & $\mathrm{~F}$ & $-1.13[-40.49,38.24]$ & 0.955 & 0 \\
\hline Over-dominant model (G/mutant vs. GG + mutant/mutant) & 2 & $\mathrm{~F}$ & $-16.32[-47.39,14.75]$ & 0.303 & 0 \\
\hline
\end{tabular}

Mutant type included TT, TA, or AA. WMD, weighted mean difference; F, fixed model; R, random model. 95\% Cl, 95\% confidence interval.

\section{Discussion}

Sirolimus (SRL) is a necessary immunosuppressive drug after renal transplantation. Nevertheless, SRL exhibit significant interindividual variability in pharmacokinetics (23). It is necessary for therapeutic drug monitoring to avoid under or over-immunosuppression. It has been suggested that $A B C B 1$ polymorphisms contribute to the variability of SRL pharmacokinetics and therapeutic outcome (24). Although the influence of $A B C B 1$ polymorphisms on SRL metabolism has been studied focusing on C3435T, C1236T, and G2677T/A, the relationship between ABCB1 polymorphism and SRL metabolism in patients is still unclear. Therefore, our study was to explore the relationship between $A B C B 1$ polymorphisms and the pharmacokinetics of SRL in renal transplantation by a meta-analysis of existing data. Our work is helpful to evaluate that whether $A B C B 1$ genetic testing is expected to play a role in guiding the individualized treatment of SRL.

The AUC is challenging to apply in clinical practice, so other indicators such as trough concentration $\left(\mathrm{C}_{0}\right)$ replace the AUC (25). That is why AUC is rarely reported in these included studies. To make a comparison between the different doses, the dosage adjusted trough concentration $\mathrm{C} / \mathrm{D}$ ratio was adopted in our study.

$A B C B 1$ C3435T, a silent SNP localized in exon 26, has been found to be associated with altered P-GP function. It was reported that the homozygosity for the $\mathrm{T}$ allele resulted in a 2-fold reduction in intestinal P-GP expression (26). However, our overall analysis of pooled results demonstrated no statistically significant association between the $\mathrm{C} / \mathrm{D}$ ratio of SRL and $A B C B 1 \mathrm{C} 3435 \mathrm{~T}$ polymorphism in different genetic models. In addition, relatively obvious heterogeneities existed in our study. With the aim of detecting the source of heterogeneity, we conducted stratified analysis according to the ethnicity and the interval after transplantation. The results were consistent with the overall analysis. Therefore, so far, there was no enough evidence showing the clinical relevance of the $A B C B 1 \mathrm{C} 3435 \mathrm{~T}$ polymorphism and the dosage adjusted trough concentration of SRL in Caucasians or Asians. 
Significant association were observed between $A B C B 1$ $\mathrm{C} 1236 \mathrm{~T}$ polymorphism and $\mathrm{C} / \mathrm{D}$ ratio of sirolimus in all patients via the homozygous model (TT vs. CC). The following subgroup analysis indicated the ethnicity of the renal transplant recipients might be one of the most critical covariates that could influence the dose adjusted concentration of SRL. The result showed that homozygous mutated genotype TT had a significant impact on the C/ $\mathrm{D}$ ratio of sirolimus in Caucasians but nor in Asians. It was also found that the dose adjusted concentrations of SRL in Caucasian patients with $A B C B 1 \mathrm{C} 1236 \mathrm{~T}$ CC carriers are significantly higher than TT carriers. Therefore, Caucasian renal transplant recipients $A B C B 1$ C1236T TT carriers might need higher doses of SRL than CC carriers recipients.

The triallelic SNP G2677T/A results in a change of the amino acid alanine into serine or threonine (27) and may alter drug transport (28), whereas the synonymous SNP C3435T and C1236T are a silent mutation that do not lead to an amino acid change. The pooled analysis of studies focusing on G2677T polymorphism(alleles $\mathrm{G}$ and $\mathrm{T}$ ) suggested that the polymorphism has significant influence on the C/D ratio of SRL. Patients carrying G2677T homozygous genotype TT would require higher doses of SRL to reach target levels compared with the wild genotype GG. However, The results of the pooled analysis about G2677mutant polymorphism (alleles G, A and T) showed no significant differences between $A B C B 1$ G2677mutant and the C/D ratio of SRL within all the genetic models. The small sample size may limit the analysis.

While each of the polymorphisms in the $A B C B 1$ haplotype may be independent, they may produce a much more salient phenotype when they appear together. One study was performed associated between ABCB1 C1236T/G2677T/ C3435T haplotypes analyses and the C/D ratio of SRL. Among the haplotypes, TTT, TGC, and CGC were the most frequently observed (29). Lee et al. (18) showed that patients carrying the CGC/CGC diplotype had a significantly lower C/D ratio of SRL compared with those carrying the CGC/ TTT and TTT/TTT diplotype $(\mathrm{P}<0.05)$.

This meta-analysis pooled available data from eligible studies and significantly increased the statistical reliability. Also, there are some advantages to this metaanalysis. Firstly, this research is the first one to estimate the association between $A B C B 1$ polymorphism and the dosage adjusted concentration of SRL in renal transplant recipients. Secondly, the subgroup for the stratified analysis of potential sources of heterogeneity was performed based on ethnicity and the interval after transplantation. Thirdly, this study systematically analyzed the six genetic models to explore the association between the dosage adjusted concentration of SRL and $A B C B 1$ polymorphism.

Although the meta-analysis conducted considerable retrieval and analysis, there are still several limitations existed. First of all, high heterogeneity existed in more than half of outcomes, and lots of factors could lead to heterogeneity, such as differences among various therapy regimens, disease staging, age, sex and method of genotype and concentration detecting. However, the complete data were hardly accessed to perform subgroup analysis. Some of these factors might further influenced the results. Second, several eligible studies are excluded due to the absence of available original data, which may have an impact on this meta-analysis. Third, the sample sizes of the included studies were relatively small. Further studies are expected to provide high-quality evidence.

\section{Conclusions}

In summary, this meta-analysis showed that no significant association exists between $A B C B 1 \mathrm{C} 3435 \mathrm{~T}$ polymorphisms and the $\mathrm{C} / \mathrm{D}$ ratio of SRL in renal transplant recipients. However, compared with $A B C B 1$ C1236T CC carriers, those with TT genotype will require a higher dose of sirolimus to achieve target therapeutic concentrations in Caucasian renal transplant recipients. ABCB1 G2677T/A TT genotype will require a higher dose of sirolimus than wild type GG genotype. Performing ABCB1 C1236T and G2677T genotyping before transplantation may guide to improve the individual immunosuppressive therapy. Further studies with large sample size are expected to confirm the relationship of $A B C B 1$ polymorphisms and the pharmacokinetics of SRL in renal transplant recipients.

\section{Acknowledgments}

Funding: This work was supported by the Beijing Municipal Natural Science Foundation (grant No. 7192218).

\section{Footnote}

Conflicts of Interest: The authors have no conflicts of interest to declare.

Ethical Statement: The authors are accountable for all aspects of the work in ensuring that questions related 
to the accuracy or integrity of any part of the work are appropriately investigated and resolved.

Open Access Statement: This is an Open Access article distributed in accordance with the Creative Commons Attribution-NonCommercial-NoDerivs 4.0 International License (CC BY-NC-ND 4.0), which permits the noncommercial replication and distribution of the article with the strict proviso that no changes or edits are made and the original work is properly cited (including links to both the formal publication through the relevant DOI and the license). See: https://creativecommons.org/licenses/by-ncnd/4.0/.

\section{References}

1. Webster AC, Lee VW, Chapman JR, et al. Target of rapamycin inhibitors (sirolimus and everolimus) for primary immunosuppression of kidney transplant recipients: a systematic review and meta-analysis of randomized trials. Transplan=tation 2006;81:1234-48.

2. Woodworth TG, Furst DE. Timely renal transplantation for scleroderma end-stage kidney disease patients can improve outcomes and quality of life. Ann Transl Med 2019;7:60.

3. Haeri A, Osouli M, Bayat F, et al. Nanomedicine approaches for sirolimus delivery: a review of pharmaceutical properties and preclinical studies. Artif Cells Nanomed Biotechnol 2018;46:1-14.

4. Renders L, Frisman M, Ufer M, et al. CYP3A5 genotype markedly influences the pharmacokinetics of tacrolimus and sirolimus in kidney transplant recipients. Clin Pharmacol Ther 2007;81:228-34.

5. Liu YY, Li C, Cui Z, et al. The effect of ABCB1 C3435T polymorphism on pharmacokinetics of tacrolimus in liver transplantation: A meta-analysis. Gene 2013;531:476-88.

6. Lampen A, Zhang Y, Hackbarth I, et al. Metabolism and transport of the macrolide immunosuppressant sirolimus in the small intestine. J Pharmacol Exp Ther 1998;285:1104-12.

7. Ambudkar SV, Kim IW, Sauna ZE. The power of the pump: Mechanisms of action of P-glycoprotein (ABCB1). Eur J Pharm Sci 2006;27:392-400.

8. Sakaeda T, Nakamura T, Okumura K. Pharmacogenetics of MDR1 and its impact on the pharmacokinetics and pharmacodynamics of drugs. Pharmacogenomics 2003;4:397-410.

9. Rosso Felipe C, de Sandes TV, Sampaio ELM, et al. Clinical Impact of Polymorphisms of Transport Proteins and Enzymes Involved in the Metabolism of Immunosuppressive Drugs. Transplant Proc 2009;41:1441-55.

10. Miao LY, Huang CR, Hou JQ, et al. Association study of $\mathrm{ABCB} 1$ and CYP3A5 gene polymorphisms with sirolimus trough concentration and dose requirements in Chinese renal transplant recipients. Biopharm Drug Dispos 2008;29:1-5.

11. Anglicheau D, Le Corre D, Lechaton S, et al. Consequences of Genetic Polymorphisms for Sirolimus Requirements After Renal Transplant in Patients on Primary Sirolimus Therapy. Am J Transplant 2005;5:595-603.

12. Cattaneo D, Baldelli S, Perico N. Pharmacogenetics of immunosuppressants: progress, pitfalls and promises. Am J Transplant 2008;8:1374-83.

13. Sam WJ, Chamberlain CE, Lee SJ, et al. Associations of ABCB1 3435C > T and IL-10-1082G $>$ A polymorphisms with long-term sirolimus dose requirements in renal transplant patients. Transplantation 2011;92:1342-7.

14. Pauli-Magnus C, Kroetz DL. Functional implications of genetic polymorphisms in the multidrug resistance gene MDR1 (ABCB1). Pharm Res 2004;21:904-13.

15. Moher D, Liberati A, Tetzlaff J, et al. Preferred reporting items for systematic reviews and meta-analyses: The PRISMA statement. Int J Surg 2010;8:336-41.

16. Jiang ZP, Wang YR, Xu P, et al. Meta-analysis of the effect of MDR1 C3435T polymorphism on cyclosporine pharmacokinetics. Basic Clin Pharmacol Toxicol 2008;103:433-44.

17. Zeng X, Zhang Y, Kwong JS, et al. The methodological quality assessment tools for preclinical and clinical studies, systematic review and meta-analysis, and clinical practice guideline: a systematic review. J Evid Based Med 2015;8:2-10.

18. Lee J, Huang $\mathrm{H}$, Chen $\mathrm{Y}$, et al. ABCB1 haplotype influences the sirolimus dose requirements in Chinese renal transplant recipients. Biopharm Drug Dispos 2014;35:164-72.

19. Li Y, Yan L, Shi Y, et al. CYP3A5 and ABCB1 genotype influence tacrolimus and sirolimus pharmacokinetics in renal transplant recipients. Springerplus 2015;4:637.

20. Rodríguez-Jiménez C, Garcia-Saiz M, Perez-Tamajon L, et al. Influence of genetic polymorphisms of CYP3A5 and $\mathrm{ABCB} 1$ on sirolimus pharmacokinetics, patient and graft survival and other clinical outcomes in renal transplant. Drug Metab Pers Ther 2017;32:49-58. 
21. Mourad M, Mourad G, Wallemacq P, et al. Sirolimus and tacrolimus trough concentrations and dose requirements after kidney transplantation in relation to CYP3A5 and MDR1 polymorphisms and steroids. Transplantation 2005;80:977-84

22. Sakurai A, Onishi Y, Hirano H,et al. Quantitative structure--activity relationship analysis and molecular dynamics simulation to functionally validate nonsynonymous polymorphisms of human $\mathrm{ABC}$ transporter ABCB1 (P-glycoprotein/MDR1). Biochemistry 2007;46:7678-93.

23. Kahan BD, Napoli KL, Kelly PA, et al. Therapeutic drug monitoring of sirolimus: correlations with efficacy and toxicity. Clin Transplant 2000;14:97-109.

24. Su L, Yin L, Yang J, et al. Correlation between gene polymorphism and blood concentration of calcineurin inhibitors in renal transplant recipients: An overview of systematic reviews. Medicine 2019;98:e16113.

25. Mahalati K, Belitsky P, Sketris I, et al. Neoral monitoring by simplified sparse sampling area under

Cite this article as: Shao $\mathrm{S}, \mathrm{Hu} \mathrm{L}$, Han Z, Hou K, Fang $\mathrm{H}$, Zhang G, Feng Y, Huang L. The effect of $A B C B 1$ polymorphism on sirolimus in renal transplant recipients: a meta-analysis. Transl Androl Urol 2020;9(2):673-683. doi: 10.21037/ tau.2020.03.42 the concentration-time curve: its relationship to acute rejection and cyclosporine nephrotoxicity early after kidney transplantation. Transplantation 1999;68:55-62.

26. Singh R, Srivastava A, Kapoor R, et al. Do drug transporter (ABCB1) SNPs influence cyclosporine and tacrolimus dose requirements and renal allograft outcome in the posttransplantation period? J Clin Pharmacol 2011;51:603-15.

27. Haerian BS, Lim KS, Tan CT, et al. Association of ABCB1 gene polymorphisms and their haplotypes with response to antiepileptic drugs: a systematic review and meta-analysis. Pharmacogenomics 2011;12:713-25.

28. Loo TW, Clarke DM. Functional consequences of proline mutations in the predicted transmembrane domain of P-glycoprotein. J Biol Chem 1993;268:3143-9.

29. Tang K, Ngoi SM, Gwee PC, et al. Distinct haplotype profiles and strong linkage disequilibrium at the MDR1 multidrug transporter gene locus in three ethnic Asian populations. Pharmacogenetics 2002;12:437-50. 
Study C1236T Homozygous model (TT vs. CC)

ID
$\%$

Weight

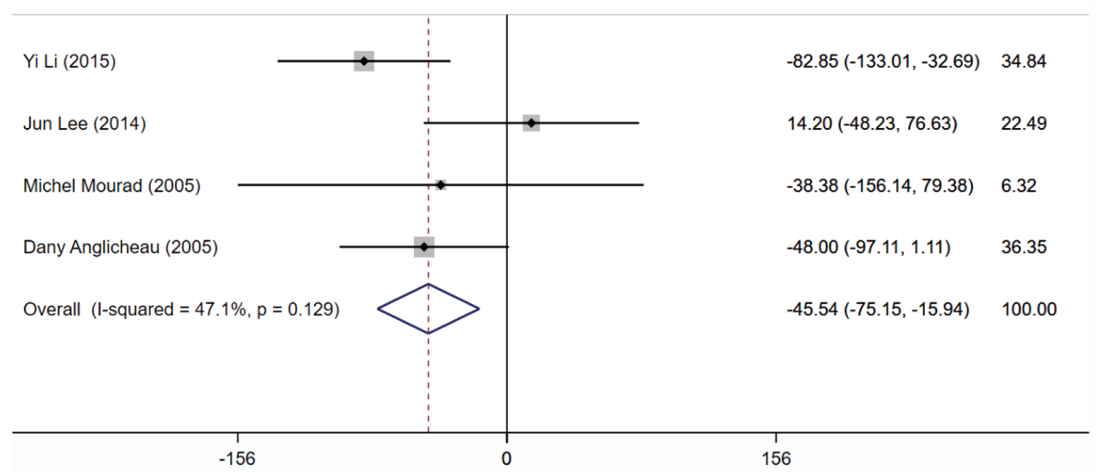

Figure S1 Forest plot of sirolimus dose-adjusted concentration between subjects carrying ABCB1 C1236T TT genotype and CC genotype by the fixed-effects model in a homozygous model.

Study C1236T Homozygous model (TT vs. CC) in the Caucasian subgroup

ID

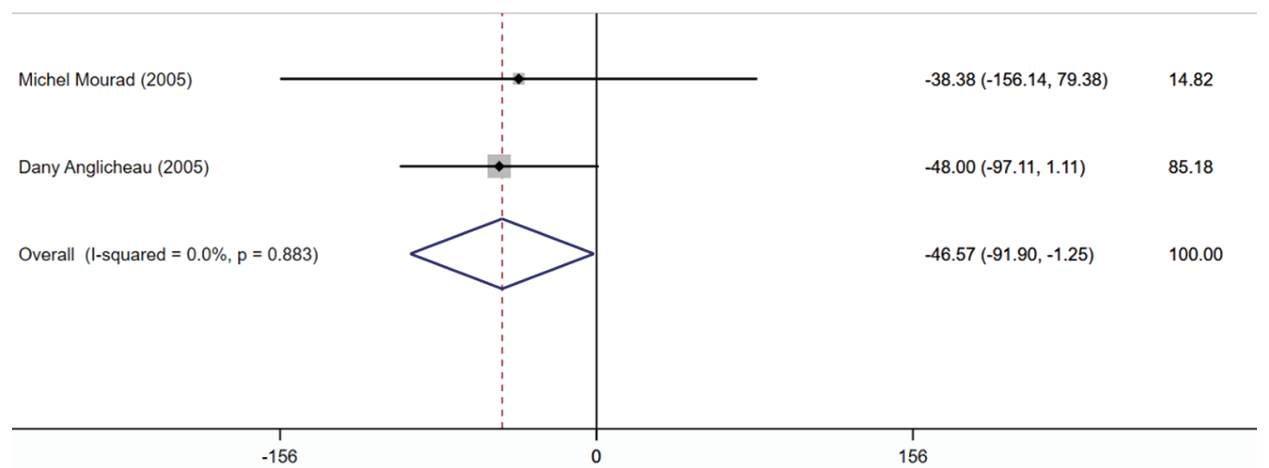

Figure S2 Forest plot of meta-analysis of dose-adjusted concentration of sirolimus administration between subjects carrying TT genotype and carrying CC genotype at $A B C B 1 \mathrm{C} 1236 \mathrm{~T}$ by the fixed-effects model in the Caucasian subgroup. 
ID

WMD $(95 \% \mathrm{Cl}) \quad$ Weight

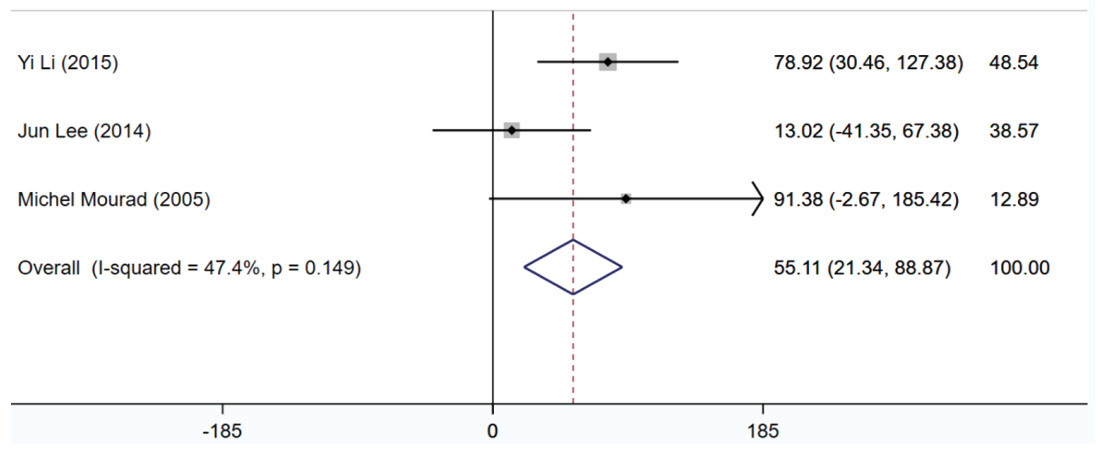

Figure S3 Forest plot of meta-analysis of dose-adjusted concentration of sirolimus administration between subjects carrying CT + TT genotype and carrying $\mathrm{CC}$ genotype at $A B C B 1 \mathrm{C} 1236 \mathrm{~T}$ by the fixed-effects model in Asian subgroup.

Study C1236T Recessive model (TT vs. CC+CT) in the Caucasian subgroup

ID

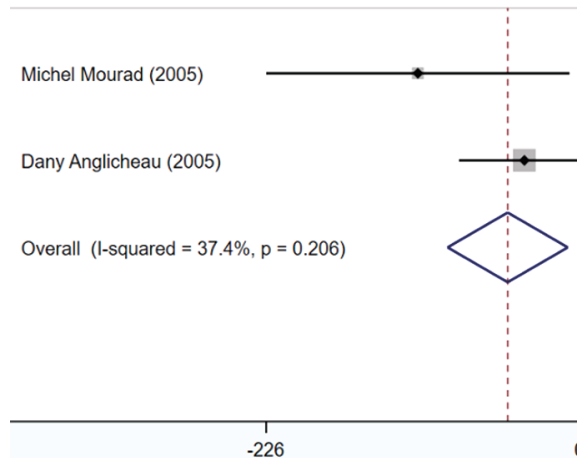

$\%$

WMD $(95 \% \mathrm{Cl}) \quad$ Weight

$-40.06(-87.20,7.08) \quad 84.29$

$-52.10(-95.38,-8.82) \quad 100.00$

Figure S4 Forest plot of meta-analysis of dose-adjusted concentration of sirolimus administration between subjects carrying TT genotype and carrying $\mathrm{CC}+\mathrm{CT}$ genotype at $A B C B 1 \mathrm{C} 1236 \mathrm{~T}$ by the fixed-effects model in the Caucasian subgroup. 
WMD $(95 \% \mathrm{Cl}) \quad$ Weight

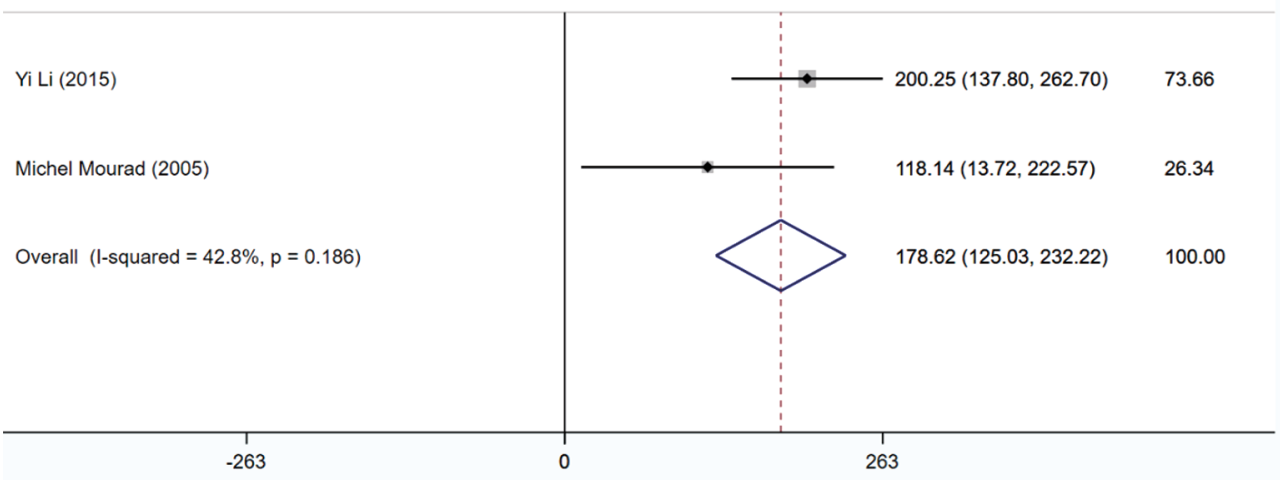

Figure S5 Forest plot of meta-analysis of dose-adjusted concentration of sirolimus administration between subjects carrying GT genotype and carrying GG genotype at $A B C B 1 \mathrm{G} 2677 \mathrm{~T}$ by fixed-effects model.

Study G2677T Homozygous model (TT vs. GG)

ID
WMD $(95 \% \mathrm{Cl})$

$-82.85(-138.18,-27.52)$

8131

Yi Li (2015)

Michel Mourad (2005)

Overall (I-squared $=0.0 \%, p=0.601$ )

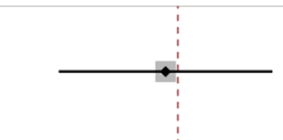

$-48.72(-164.16,66.71)$

$-76.47(-126.37,-26.58)$

100.00
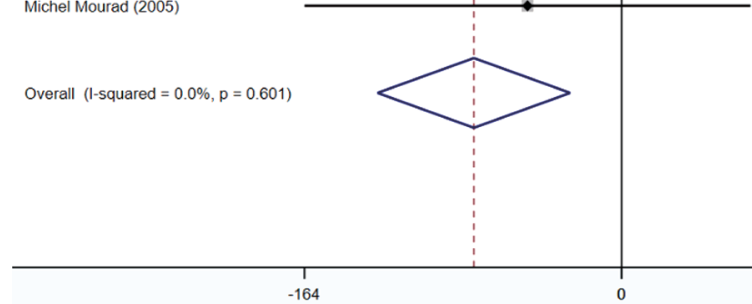

Weight 
ID

WMD $(95 \% \mathrm{Cl}) \quad$ Weight

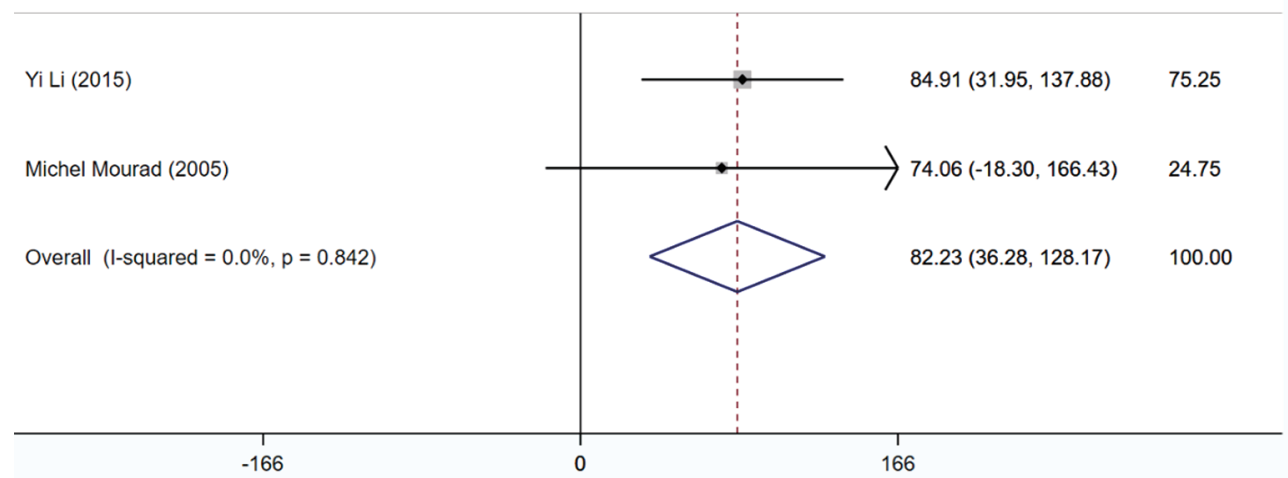

Figure S7 Forest plot of meta-analysis of dose-adjusted concentration of sirolimus administration between subjects carrying GT+TT genotype and carrying GG genotype at $A B C B 1$ G2677T by fixed-effects model.

Study G2677T Recessive model (TT vs. GG+GT)

ID

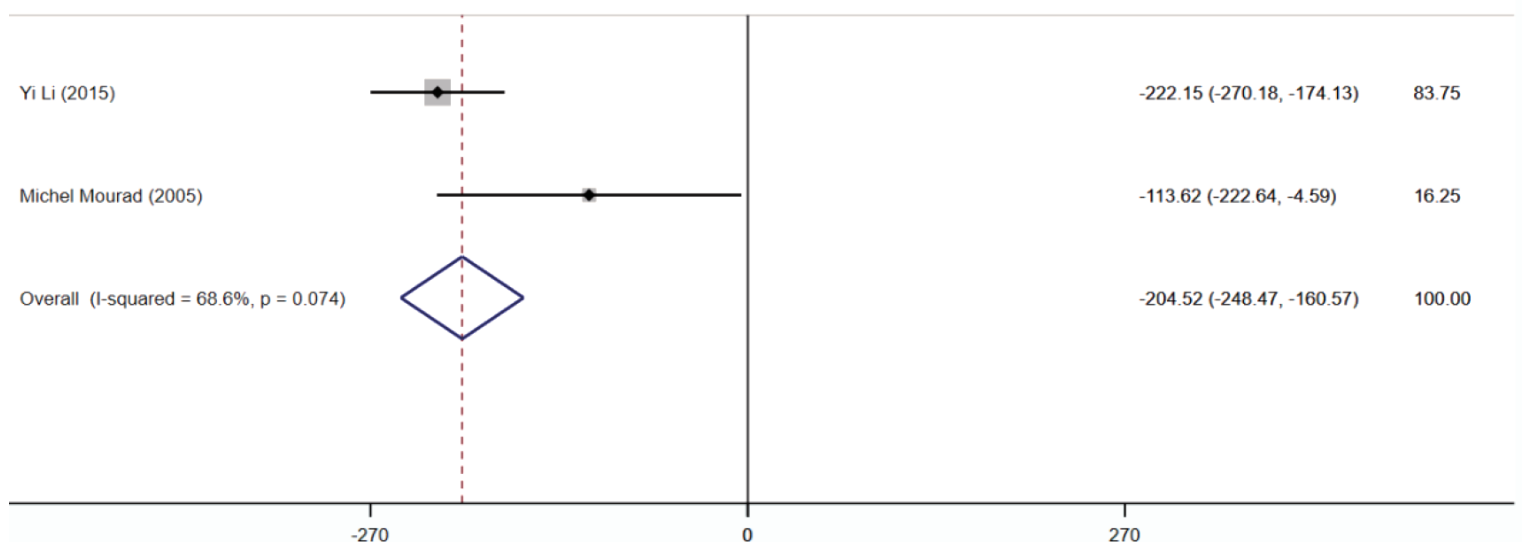

Figure S8 Forest plot of meta-analysis of dose-adjusted concentration of sirolimus administration between subjects carrying TT genotype and carrying GG + GT genotype at $A B C B 1 \mathrm{G} 2677 \mathrm{~T}$ by fixed-effects model. 


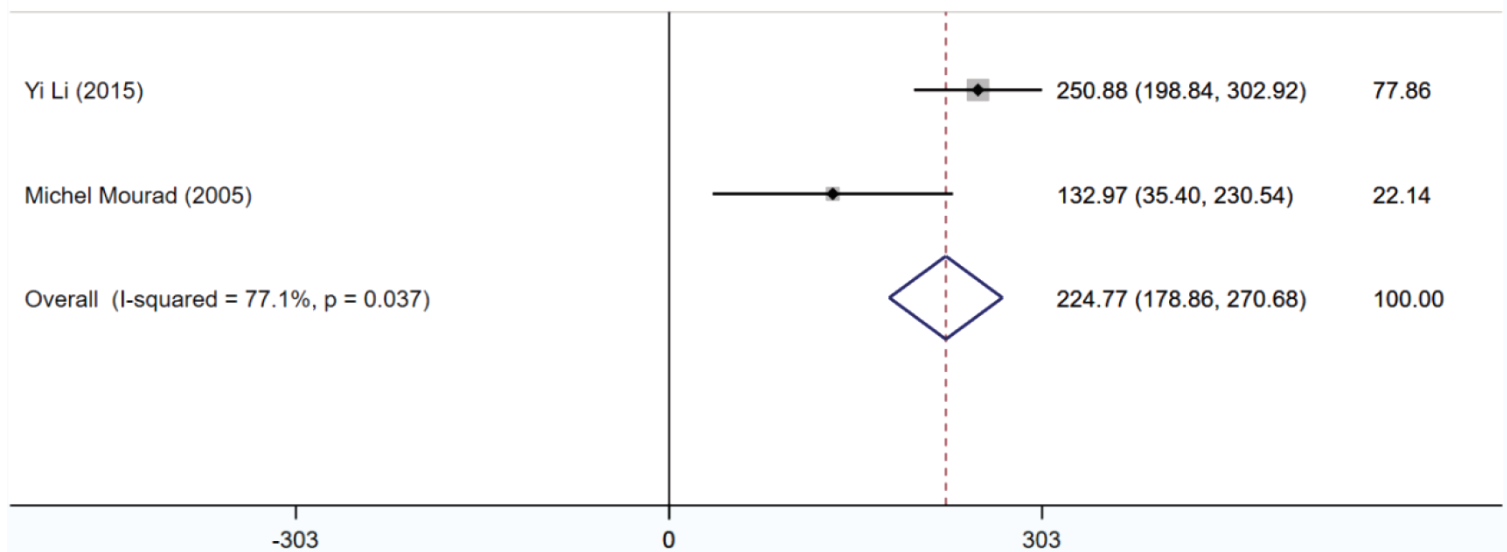

Figure S9 Forest plot of meta-analysis of dose-adjusted concentration of sirolimus administration between subjects carrying GT genotype and carrying GG + TT genotype at ABCB1 G2677T by fixed-effects model.

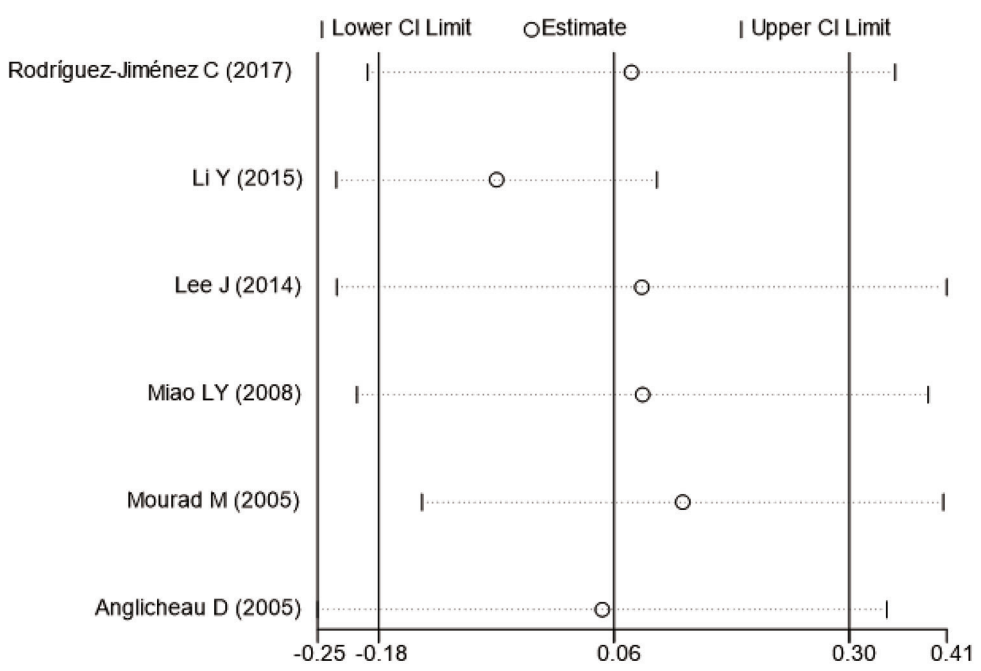

Figure S10 Sensitivity analysis for $A B C B 1 \mathrm{C} 3435 \mathrm{~T}$ polymorphism with the dose-adjusted concentration of sirolimus. 


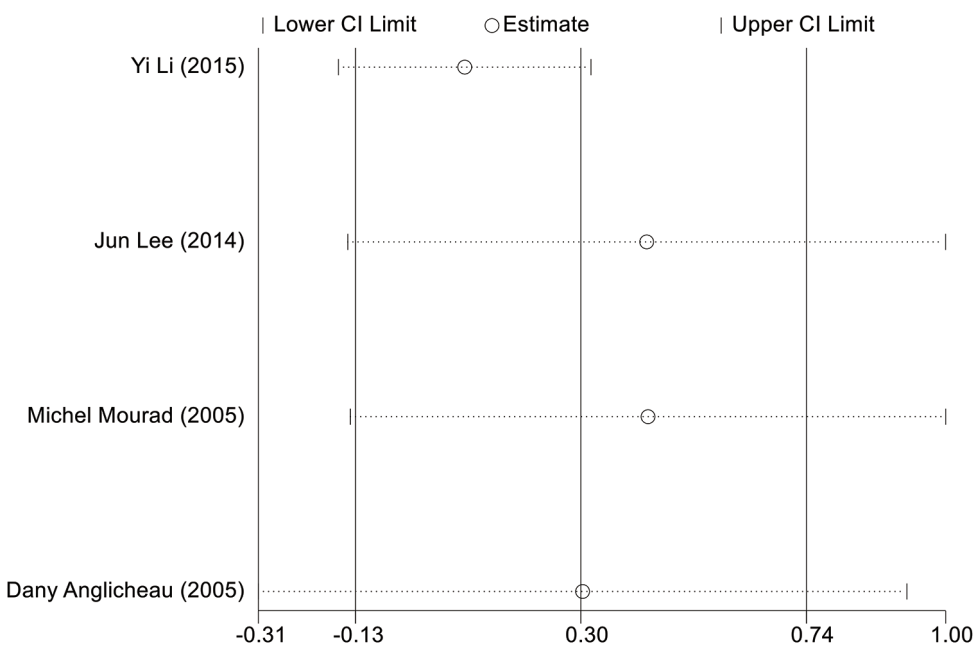

Figure S11 Sensitivity analysis for $A B C B 1 \mathrm{C} 1236 \mathrm{~T}$ polymorphism with the dose-adjusted concentration of sirolimus.

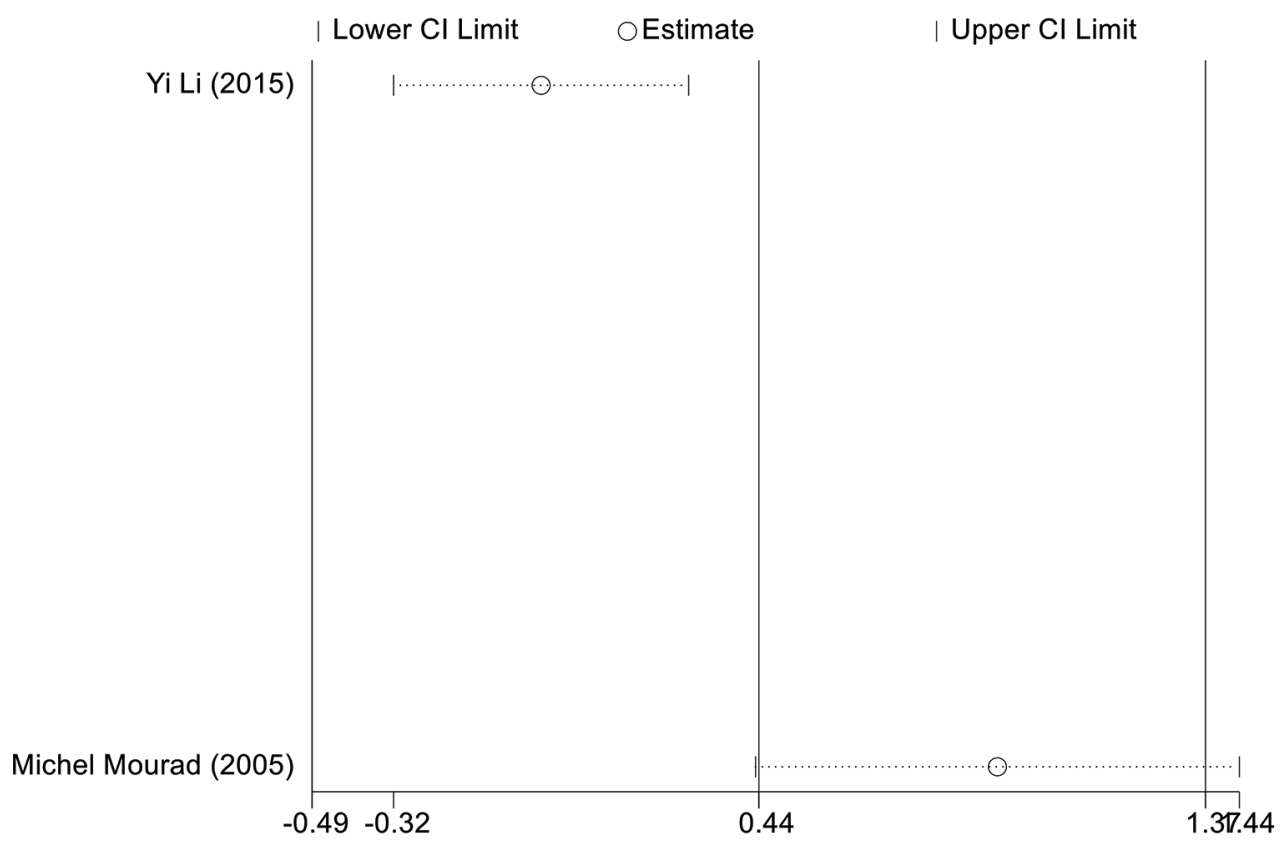

Figure S12 Sensitivity analysis for $A B C B 1$ G2677T polymorphism with the dose-adjusted concentration of sirolimus. 


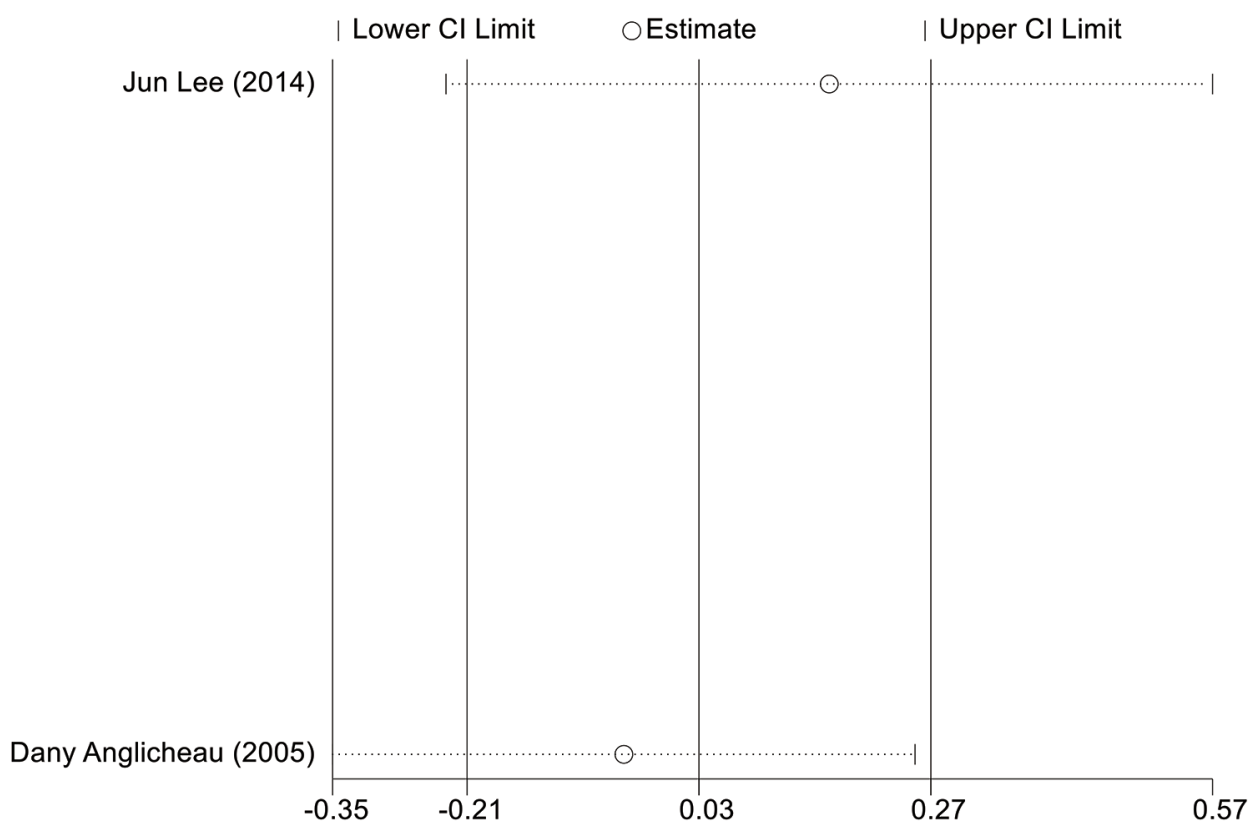

Figure S13 Sensitivity analysis for $A B C B 1$ G2677mutant polymorphism with the dose-adjusted concentration of sirolimus.

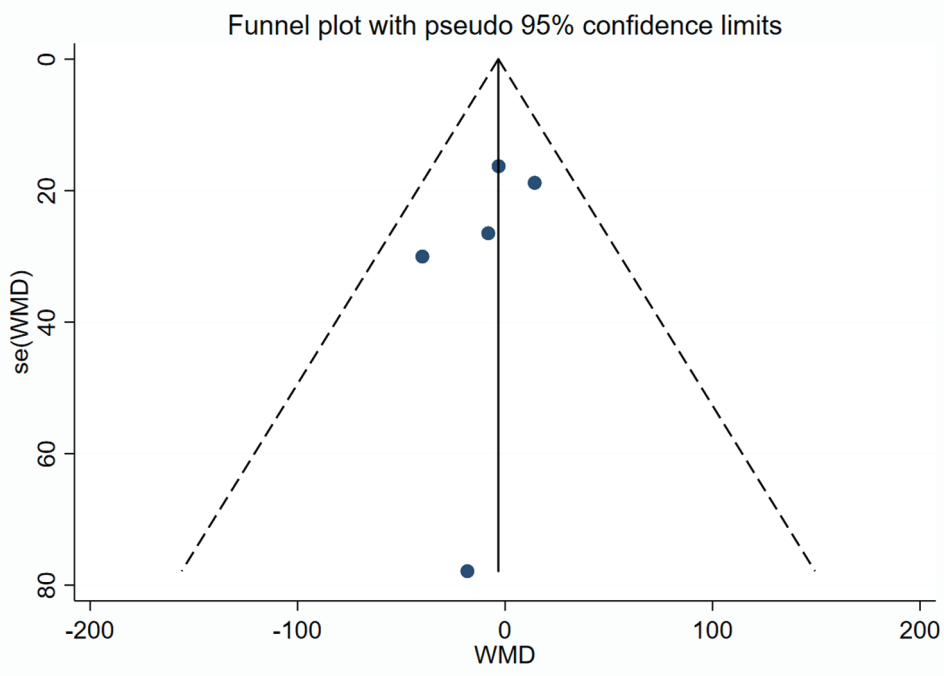

Figure S14 Funnel plots of the association between $A B C B 1$ C3435T polymorphism and dose-adjusted concentration of sirolimus. 


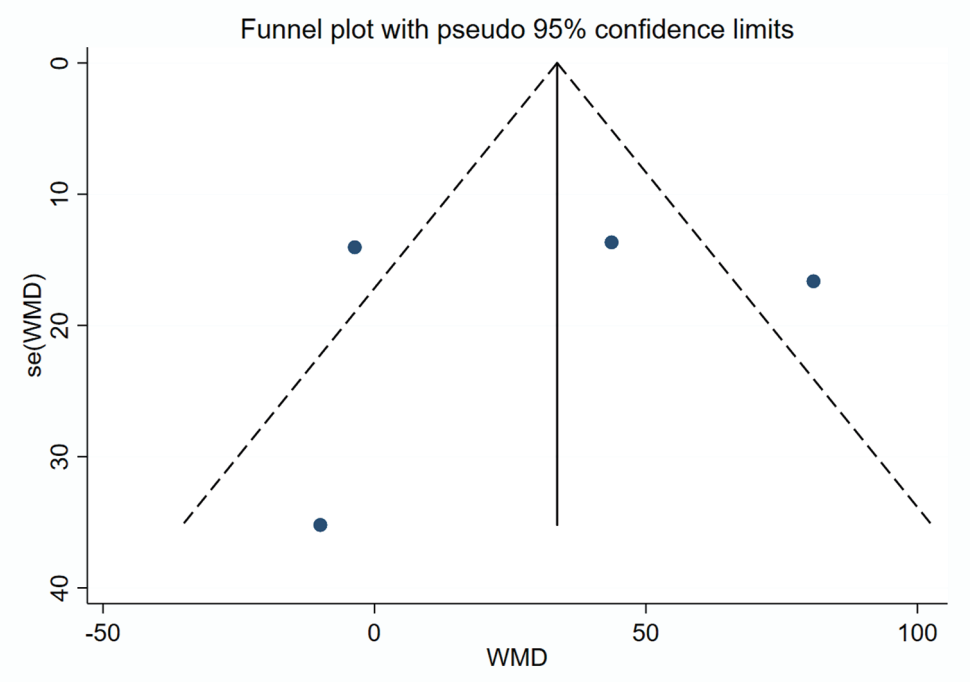

Figure S15 Funnel plots of the association between $A B C B 1 \mathrm{C} 1236 \mathrm{~T}$ polymorphism and dose-adjusted concentration of sirolimus.

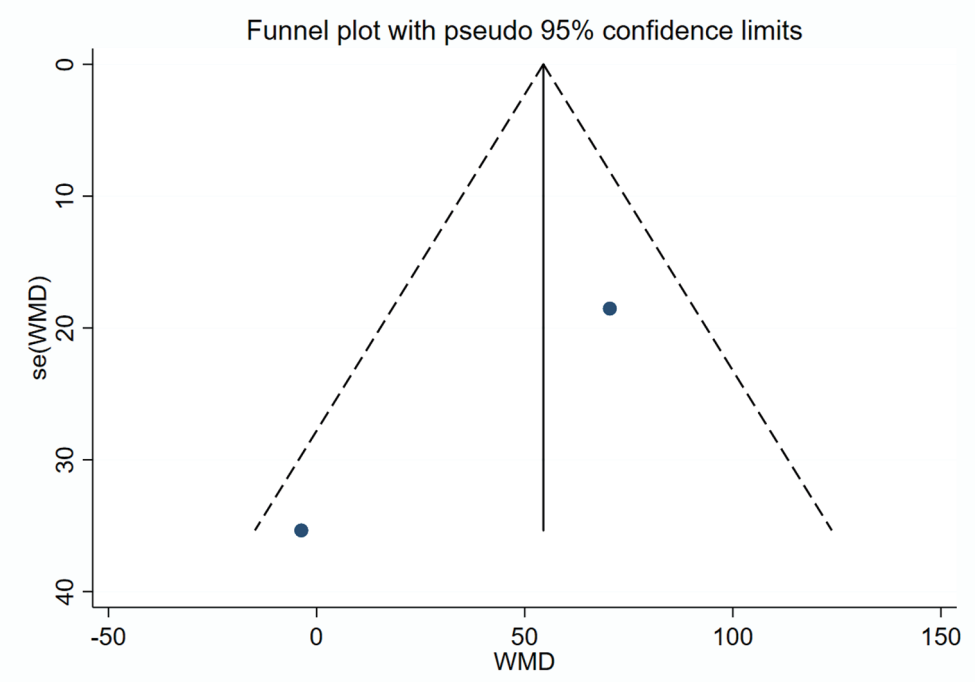

Figure S16 Funnel plots of the association between $A B C B 1$ G2677T polymorphism and dose-adjusted concentration of sirolimus. 


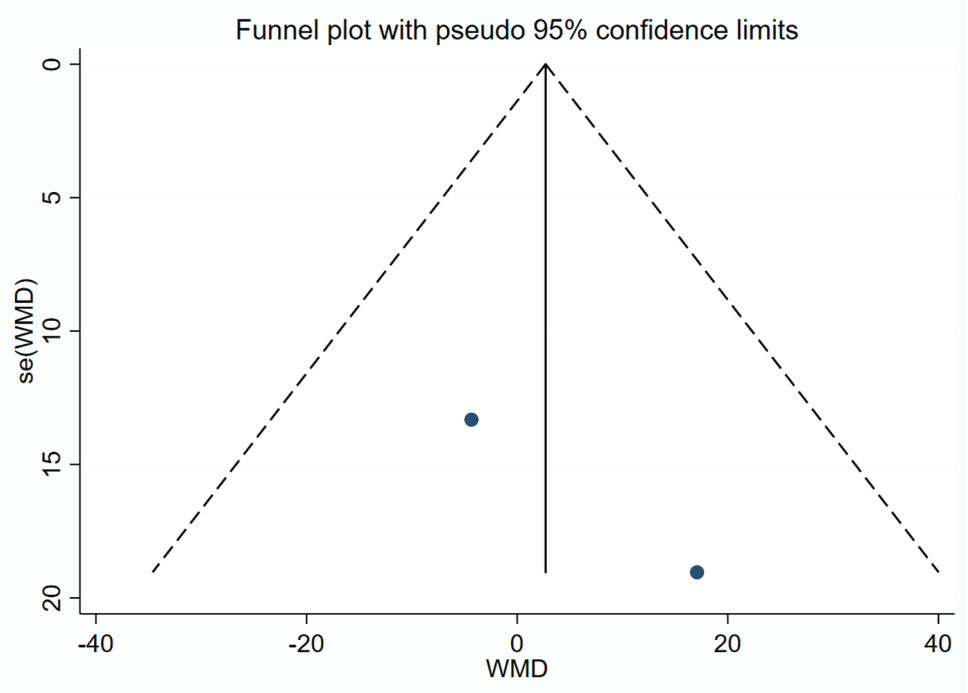

Figure S17 Funnel plots of the association between $A B C B 1$ G2677mutant polymorphism and dose-adjusted concentration of sirolimus. 
Table S1 The P value of Egger's test and Begg's test for publication

\begin{tabular}{|c|c|c|}
\hline Genetic models & $\begin{array}{l}\text { Begg's } \\
\text { test-P }\end{array}$ & $\begin{array}{l}\text { Egger's } \\
\text { test-P }\end{array}$ \\
\hline \multicolumn{3}{|l|}{ C3435T } \\
\hline \multicolumn{3}{|c|}{ Allelic model (T vs. C) } \\
\hline Overall & 0.707 & 0.415 \\
\hline Asian & 0.734 & 0.433 \\
\hline Caucasian & 1.000 & 0.641 \\
\hline$\geq 3$ months & 0.462 & 0.411 \\
\hline$\geq 6$ months & 1.000 & - \\
\hline \multicolumn{3}{|c|}{ Heterozygous model (CT vs. CC) } \\
\hline Overall & 0.452 & 0.246 \\
\hline Asian & 0.308 & 0.521 \\
\hline Caucasian & 1.000 & 0.397 \\
\hline$\geq 3$ months & 0.806 & 0.528 \\
\hline$\geq 6$ months & 1.000 & - \\
\hline \multicolumn{3}{|c|}{ Homozygous model (TT vs. CC) } \\
\hline Overall & 0.806 & 0.297 \\
\hline Asian & 0.734 & 0.415 \\
\hline Caucasian & 1.000 & - \\
\hline$\geq 3$ months & 0.308 & 0.217 \\
\hline$\geq 6$ months & 1.000 & - \\
\hline \multicolumn{3}{|c|}{ Dominant model (CT + TT vs. CC) } \\
\hline Overall & 0.452 & 0.175 \\
\hline Asian & 1.000 & 0.378 \\
\hline Caucasian & 0.296 & 0.102 \\
\hline$\geq 3$ months & 0.806 & 0.325 \\
\hline$\geq 6$ months & 1.000 & - \\
\hline \multicolumn{3}{|c|}{ Recessive model (TT vs. CC + CT) } \\
\hline Overall & 1.000 & 0.300 \\
\hline Asian & 1.000 & 0.385 \\
\hline Caucasian & 1.000 & - \\
\hline$\geq 3$ months & 0.734 & 0.355 \\
\hline$\geq 6$ months & 1.000 & - \\
\hline \multicolumn{3}{|c|}{ Over-dominant model (CT vs. CC + TT) } \\
\hline Overall & 0.707 & 0.518 \\
\hline Asian & 0.734 & 0.952 \\
\hline Caucasian & 1.000 & 0.707 \\
\hline$\geq 3$ months & 1.000 & 0.751 \\
\hline$\geq 6$ months & 1.000 & - \\
\hline \multicolumn{3}{|l|}{ C1236T } \\
\hline \multicolumn{3}{|c|}{ Allelic model (T vs. C) } \\
\hline Overall & 1.000 & 0.868 \\
\hline Asian & 1.000 & 0.957 \\
\hline Caucasian & 1.000 & - \\
\hline$\geq 3$ months & 1.000 & 0.767 \\
\hline \multicolumn{3}{|c|}{ Heterozygous model (CT vs. CC) } \\
\hline Overall & 0.308 & 0.380 \\
\hline Asian & 1.000 & 0.898 \\
\hline Caucasian & 1.000 & - \\
\hline$\geq 3$ months & 0.296 & 0.072 \\
\hline \multicolumn{3}{|c|}{ Homozygous model (TT vs. CC) } \\
\hline Overall & 0.734 & 0.673 \\
\hline Asian & 1.000 & 0.786 \\
\hline Caucasian & 1.000 & - \\
\hline$\geq 3$ months & 1.000 & 0.891 \\
\hline \multicolumn{3}{|c|}{ Dominant model (CT + TT vs. CC) } \\
\hline Overall & 0.734 & 0.291 \\
\hline Asian & 1.000 & 0.847 \\
\hline Caucasian & 1.000 & - \\
\hline$\geq 3$ months & 0.296 & 0.100 \\
\hline \multicolumn{3}{|c|}{ Recessive model ( $\Pi$ vs. $C C+C T)$} \\
\hline Overall & 1.000 & 0.992 \\
\hline Asian & 1.000 & 0.992 \\
\hline Caucasian & 1.000 & - \\
\hline$\geq 3$ months & 0.296 & 0.100 \\
\hline Over-dominant & & \\
\hline Overall & 0.308 & 0.573 \\
\hline Asian & 1.000 & 0.826 \\
\hline Caucasian & 1.000 & - \\
\hline$\geq 3$ months & 0.296 & 0.220 \\
\hline
\end{tabular}

